\title{
Modelling the Australasian Financial Cycle: A Markov-Regime Switching Approach
}

Milan Christian de Wet

University of Johannesburg

\begin{tabular}{l}
\hline ARTICLE INFO \\
\hline Article History \\
Received 24 May 2021 \\
Accepted 15 July 2021 \\
\hline JEL Classifications \\
G32, L25, L30, O34
\end{tabular}

ABSTRACT

\section{Purpose:}

The importance of the financial cycle has become a central point of consideration for policymakers since the 2007-08 financial crisis. This study aimed to construct and characterize the aggregate Australasian financial cycle.

\section{Design/methodology/approach:}

To construct the aggregate cycle, a dynamic factor model is employed, based on credit aggregates and aggregate property prices in Australia and New Zealand. To extract the aggregate Australasian financial cycle, the Christiano-Fitzgerald bandpass filter is implemented. Also, a Markov-Regime Switching Autoregressive model is employed to model, characterize and identify asymmetries in the aggregate Australasian financial cycle.

Findings:

The results indicate that Australian credit conditions are the prominent underlying driver of the aggregate Australasian financial cycle. The aggregate Australasian financial cycle exhibits a typical duration of 45 quarters, with expansions typically lasting 25 quarters and contractions lasting 20 quarters. Australasian financial cycles thus typically last longer than business cycles. The results also provide evidence that contractions in the aggregate Australasian financial cycle are typically shorter but harsher and more volatile than cyclical expansions, and that a level of linear persistence exists in the cycle.

Research limitations/implications:

A limitation of this study is that full data sets for all the variables that constitute the aggregate Australasian financial cycle is only available from 1978Q1. Therefore, the time horizon of the study starts at this point. However, given the long typical long duration of financial cycles, it would be ideal to have a time horizon of about 100 years. The implications

Keywords:

Financial cycle, dynamic factor model, Markov-

Switching, cyclical extraction, cyclical asymmetries of asymmetry in the aggregate cycle have several policy implications. Asymmetries might necessitate different policy strategies, as well as influence the timing of implementing policies during different financial cycle phases. The durational asymmetry in the aggregate financial cycle, whereby expansions in the aggregate financial cycle are typically longer than contractions, indicates that the employment of restrictive monetary and macroprudential policies should be implemented for longer periods than accommodative policies. Also, given that contractions in the aggregate financial cycle are steeper than expansions, policy response should be quicker and should be stronger with accommodative monetary policies once the aggregate financial cycle is in a contraction phase, relative to restrictive monetary policies during an expansion phase.

Originality/value:The construction of a single aggregate measure that encapsulates the cyclical behaviour of a range of financial variables aids as a solution to simplify the study of aggregate financial cycles. In this light, this study contributes to the body of empirical literature on Australasian economic cycles by providing a single aggregate Australasian financial cycle measure that encapsulates the cyclical behaviour of several financial variables from two of the biggest economies in this region. This will provide policymakers with a single measure to consider the cyclical state of financial aggregates in Australasia. This study further contributes by establishing cyclical durations and identifying asymmetries in the cycle. Such an analysis aid in gaining a deeper understanding of the aggregate Australasian financial cycle and provide a means to improve the accuracy of predicting future movements in the financial cycle. This, in turn, could aid policymakers to manage fluctuations in the aggregate financial cycle and thereby reduce the potentially adverse effect of financial cycle fluctuations.

${ }^{\dagger}$ Corresponding Author: Milan Christian de Wet

Email: miland@uj.ac.za 


\section{Introduction}

Financial conditions are playing an increasingly important role in the economy, as a result, financial instability and aggregate financial cyclicality have emerged as a key economic concept since the 2007/08 financial crisis. However, before the 2007/08 financial crisis, policymakers and researchers largely neglected to consider the role of financial cyclicality on the economy, considering the role played by the business cycle far more important. Therefore, knowledge and understanding of business cycles are far more extensive than on financial cycles, resulting in several knowledge gaps. $\mathrm{Ng}$ (2011) and Borio (2014) propose a definition for aggregate financial cycles, suggesting that they are self-reinforcing, reflecting the ebb and flow of aggregate value, risk sentiment and funding availabilities, often driven by changes in credit levels and asset prices. This, in turn, typically result in periods of financial expansion, followed by financial contraction. This necessitates the need to correctly identify the current financial cycle regime, in order to identify prevailing financial market risks such as excessive leverage induced asset price appreciations. As argued by Strohsal, Proaño and Wolters (2019), our understanding of the nature of the financial cycle provides the ability to anticipate future cyclical movements in this cycle and can help predict crises.

Since the financial crisis, characterising aggregate financial cycles have become a key focus of central banks and economic cycle research, in order to improve the understanding of such cycles (Strohsal et al., 2019). Timely and effective policy implementation, with the aim to manage destructive financial cycles, rely on the accurate modelling and identification of the cycle. A number of methods have been implemented in this regard, Pontines (2017), de Wet and Botha (2019) and Strohsal et al. (2019) utilise a spectral density analysis, Claessens, Kose and Terrones (2012) and Drehmann, Borio and Tsatsaronis (2012) implement a turning-point analysis and Aikman, Haldane and Nelson (2015) use Frequency-based band-pass filters. In this regard, empirical literature largely focuses on identifying the properties of financial cycles. The main findings are that financial cycles typically exhibits longer durations and larger amplitudes than the business cycle (Borio, 2014; Aikman et al., 2015 and Strohsal et al., 2019). Strohsal et al. (2019) argue that the relatively longer duration reflects the unsustainable build-up of macro-financial instabilities over an extended period of time, which then ends in a severe financial contraction with potentially disruptive economic implications. This emphasises the importance to effectively manage the financial cycle by means of timely and effective policies.

Despite the growing body of literature on financial cycles, financial cycles are far less researched and understood than the traditional business cycle, leaving a number of research gaps. Two research gaps will be considered in this study. Firstly, financial cycle research focuses largely on the financial cycle of the United States of America, the United Kingdom and the European Union. Such results can not necessarily be generalised and applied to other financial cycles, requiring research to extend to the financial cycle on a broader range of economies (Pontines, 2017). Secondly, existing research does not formally consider cyclical asymmetries in financial cycles. Cyclical asymmetries prove to exist in business cycles, with several policy implications, rendering this a key topic in business cycle research. Financial cycles could exhibit similar cyclical asymmetries, necessitating research in this regard.

The main aim of this study was to construct, model and characterise the aggregate Australasian financial cycle. The multiple dimensional aspects of financial cycles in an economy make the study and analysis of Aggregate financial cycles complex. This, in turn, complexifies policy making related to aggregate financial cycles. The construction of a single aggregate measure that encapsulates the cyclical behaviour of a range of financial variables aids as a solution to simplify the study of aggregate financial cycles. In this light, this study contributes to the body of empirical literature on Australasian economic cycles by providing a single aggregate Australasian financial cycle measure that encapsulates the cyclical behaviour of a number of financial variables from two of the biggest economies in this region. This will provide policymakers with a single measure to consider the cyclical state of financial aggregates in Australasia. This study further contributes by modelling the aggregate Australasian financial cycle with a non-linear Markov-regime switching model and thereby establishing cyclical durations, identifying asymmetries in the cycle and identifying whether cyclical persistence exists in the cycle. Such an analysis aid in gaining a deeper understanding of the aggregate Australasian financial cycle and provide a means to improve the accuracy of predicting future movements in the financial cycle. This, in turn, could aid policymakers to manage fluctuations in the aggregate financial cycle and thereby reduce the potentially adverse effect of financial cycle fluctuations. Additionally, such information can aid in the decision-making process of economic participants, such as asset managers, risk managers and business managers, who are exposed to Australasian financial cycle fluctuations.

\section{Review of Literature}

Provided the definition by $\mathrm{Ng}$ (2011) and Borio (2014), a single variable can not sufficiently be utilised to reflect aggregate financial cycle conditions. Thus, in literature, an aggregate financial cycle measure typically comprises of several variables, see for example, Claessens, et al. (2012), Borio (2014), Aikman et al. (2015), Schüler, Hiebert and Peltonen (2015), Farrell and Kemp (2020), Menden and Proano (2017) and Strohsal et al. (2019). The debate is around which variables to include in an aggregate financial cycle measure. A number of researchers, such as Claessens, et al. (2012), Borio (2014), Aikman et al. (2015), Pontines (2017) and Farrell and Kemp (2020), indicate that aggregate financial cycles are effectively proxied by property prices and credit aggregates.

Property prices reflect information about the interplay between perceived value and risk sentiment in the economy. On the other hand, credit aggregates reflect funding availabilities and often prove to be at the core of 
financial crises (Aikman et al., 2013 and Schüler et al., 2015). As argued by Aikman et al. (2013), credit expansions often result in asset price inflation and multiple expansions, whereby increases in asset prices, i.e. aggregate equity prices, diverge from their underlying fundamentals. In tandem, Farrell and Kemp (2020) write that credit aggregates and property prices create a mutually reinforcing feedback effect, whereby an expansion in credit typically result in higher property prices, and higher property prices offer higher collateral levels, which in turn typically stimulate a further credit expansion. Historically, this feedback process has resulted in some of the most serious financial buildups and financial instabilities. In addition, evidence indicates that property price booms and credit expansions often precedes financial crises (Pontines, 2017). Therefore, jointly these two variables proxies aggregate financial cyclicality.

Aggregate equity prices are often considered as a third variable to capture perceived value and risk sentiment. However, Claessens, et al. (2012) and Drehmann et al. (2012) provide evidence that equity prices can distort the financial cycle due to their short term volatility characteristics. Therefore, this study will construct the aggregate Australasian financial cycle by means of credit aggregates and property prices. Given that an aggregate financial cycle typically comprises of more than one variable, it's necessary to aggregate these variables into a single cyclical measure. To this end, dimension reduction techniques are the most common aggregation technique implemented in financial cycle literature. Such techniques include principal component analysis (PCA) and dynamic factor modelling (DFM), see for example; Stock and Watson (2011), Stock and Watson (2011), Farrell and Kemp (2020), Adarov (2018) and Strohsal et al. (2019). A DFM model will be implemented in this study, given the ability of the DFM to incorporate lag dynamics between variables.

The body of literature on financial cycles largely focus on the properties of financial cycles. $\mathrm{Ng}$ (2011), Claessens, et al. (2012), Borio (2014), Aikman et al. (2015), Pontines (2017) and Farrell and Kemp (2020) consider the properties of credit, property and equity cycles, providing evidence that credit cycles and property price cycles tend to be significantly more severe and longer than the traditional business cycle. Furthermore, Claessens, et al. (2012) provide evidence that booms are driven by credit expansions typically result in relatively deeper contractions and slower recoveries. Schularick and Taylor (2012) and Jorda, Schularick and Taylor (2016) provide similar evidence.

An important consideration in economic cycle literature is economic cycle asymmetries. In this regard, research primarily focuses on business cycles where a number of researchers, such as Goodwin (1993), Layton and Katsuura (2001), Chauvet and Hamilton (2006), Tastan and Yildirim (2008), Narayan and Pop (2009) and Breitung and Eickmeier (2015), provide evidence that business cycles often exhibit asymmetries. Empirical evidence primarily indicates that cyclical contractions are typically shorter but more volatile and steeper than expanding cycles (McQueen and Thorley, 1993; Tastan and Yildirim, 2008 and Breitung and Eickmeier, 2015). Furthermore, evidence indicates that cyclical troughs are deeper than cyclical peaks (Tastan and Yildirim, 2008 and Breitung and Eickmeier, 2015).

Financial cycles might exhibit similar asymmetries, which could have both policy and modelling implications. Yet, very limited to no research has been done on financial cycle asymmetries. The identification of such asymmetries could enhance the understanding of financial cycles and thereby make a significant policy contribution as well as enhance the modelling process of financial cycles. For example, symmetric policies measures across the financial cycle might render subpar results given cyclical asymmetries. Thus, as argued by Tastan and Yildirim (2008), the presence of cyclical asymmetries could require different policy measures and magnitudes, as well as timing adjustments during different cyclical regimes (Tastan and Yildirim, 2008).

Furthermore, by definition, linear modelling procedures are unable to identify cyclical asymmetries and are therefore unable to account for such asymmetries. Therefore, modelling financial cycles with linear models might provide sub-par results (Bouali, Nasr, and Trabelsi, 2016). Hence the argument by researchers, such as Tastan and Yildirim (2008), Sarbijan (2014) and Bouali et al. (2016), to employ non-linear methods to model cycles. The Markov regime-switching model, proposed by Hamilton (1989), is widely implemented in this regard, see, for example, Simpson, Osborn and Senier (2001), Moolman (2004), Tastan and Yildirim (2008) and Bouali et al. (2016). There are four common types of asymmetries identified in cyclical research namely: asymmetry in the steepness; asymmetry in the deepness; asymmetry in the sharpness; and asymmetry in the duration of a given cyclical measure (Tastan and Yildirim, 2008). This will further be discussed in the methodology section.

The body of literature on the business cycle of Australia and New Zealand are rich. See for example Layton (1997), Crosby (2002) and Cashin and Ouliaris (2004) on the Australian business cycle and Kim, Buckle, and Hall (1994 and 1995), Hall and McDermott (2009), Chetwin (2012) and Hall, Thomson and McKelvie (2017) on the New Zealand business cycle. However, financial cycles of these countries are far less researched. To the best of my knowledge, the only published work in this regard is the work by Davies and Gai (2020) who identified the characteristics of the New Zealand financial cycle by means of a Spectral density analysis. The findings by Davies and Gai (2020) indicate that the. New Zealand financial cycle has a duration of approximately 8 years. The paper by Davies and Gai (2020) focus only on the financial cycle of New Zealand, and does not consider any cyclical asymmetries, nor does the paper estimate the financial cycle with a model that allows for a formal hypothesis testing procedure. This study aims to extend the knowledge on Australasian financial cycles.

\section{Data Discussion}

As discussed previously, this article will consider property prices and credit aggregates as financial cycle constituents. The real long-series property price index from the Bank of International Settlements is used as a property price proxy for both Australia and New Zealand. Furthermore, total non-financial credit is used as a credit aggregate proxy for 
both Australia and New Zealand, also sourced from the Bank of International Settlements. The data frequency is quarterly and the timestamp range from 1978Q1 to 2018Q3. These measures will be aggregated into a single Australasian financial conditions index from which cycles will be extracted to represent the aggregate Australasian financial cycle.

To ensure that there are no bias loadings due to non-stationarity, the variables subjected to the DFM will be tested for unit roots by means of an Augmented Dickey-Fuller unit root test and the series will be differenced where necessary to ensure that each variable is stationary when applying the DFM (Stock and Watson, 2011). Furthermore, variables modelled with the MS-AR model will also be tested for stationarity to ensure no spurious regression. Research has shown that the standard augmented Dickey-Fuller unit root test is often sub-par when working with a time series that exhibits cycles and regime-switching properties (Nelson, Piger and Zivot, 2000). Nelson et al. (2000) suggest using the Phillips-Perron unit root test or a breakpoint augmented Dickey-Fuller unit root test, which allows for endogenous probabilistic trend fluctuations in a series when testing a cyclical series for stationarity. Therefore, a Phillips-Perron unit root test and breakpoint augmented Dickey-Fuller unit root test will be used to test the level of integration of cyclical variables to be modelled with the MS-AR model.

\section{Methodology}

This study will implement a dynamic factor model to aggregate the various variables into a single variable that will serve as an Australasian financial conditions index. A Christiano-Fitzgerald (CF) bandpass filter will then be implemented to extract cycles from the Australasian financial conditions index. The extracted cycle will then be modelled by means of a Markov-regime Switching autoregressive MS-AR model. Within the MS-AR model, Wald's hypothesis testing process will be implemented to test for various cyclical asymmetries, as suggested by Clements and Krolzig (2003).

\subsection{The dynamic factor model}

In accordance with the specification by Stock and Watson (2011), the static DFM model is specified as follows:

$$
\begin{gathered}
\mathrm{X}_{\mathrm{t}}=\lambda(\mathrm{L}) \mathrm{f}_{\mathrm{t}}+\mathrm{e}_{\mathrm{t}}(1) \\
\mathrm{f}_{\mathrm{t}}=\delta(\mathrm{L}) \mathrm{f}_{\mathrm{t}-1}+v_{\mathrm{t}}(2)
\end{gathered}
$$

Where there are $N$ series, so $X_{t}$ and $e_{t}$ are $(N \times 1)$ vectors of the observable variables in the model and errors respectively. There are $q$ dynamic factors, so $f_{t}$ and $v_{t}$ are $(q \times 1)$ vectors of dynamic factors and idiosyncratic disturbances, respectively. It is assumed that both $\mathrm{e}_{\mathrm{t}}$ and $v_{\mathrm{t}}$ are uncorrelated with the factors in the model at each lead and lag innovation.

Furthermore, $\mathrm{L}$ is the lagged operator, and the lag polynomial matrices $\lambda(\mathrm{L})$ and $\delta(\mathrm{L})$ are $(\mathrm{N} \times \mathrm{q})$ and $(\mathrm{q} \times \mathrm{q})$ lag polynomial matrices, respectively. A shortcoming of the static dynamic factor model is that $f_{t}$ are not directly estimated, limiting the practical usage of the results (Stock and Watson, 2011). Hence, in literature, the DFM is commonly estimated within a state-space and the Kalman filter is implemented to determine the Gaussian likelihood and identify the parameters by means of maximum likelihood (Stock and Watson, 2011). A state-space DFM model can be specified by adjusting the DFM specification in equations 1 and 2 as follow. Let $\mathrm{p}$ be the degree of the lag polynomial matrix $\lambda(\mathrm{L})$, let $\mathrm{F}_{\mathrm{t}}=\left(\mathrm{f}_{\mathrm{t}}^{\prime}, \mathrm{f}_{\mathrm{t}-1}^{\prime}, \ldots, \mathrm{f}_{\mathrm{t}-\mathrm{p}}^{\prime}\right)^{\prime}$ denote an $\mathrm{r} \times 1$ vector, and let $\Lambda=\left(\lambda_{0}, \lambda_{1}, \ldots, \lambda_{\mathrm{p}}\right)$, where $\lambda_{\mathrm{i}}$ is the $\mathrm{N}$ $\mathrm{x}$ q matrix of coefficients on the $\mathrm{i}^{\mathrm{th}} \operatorname{lag}$ in $\lambda(\mathrm{L})$. Also, let $(\mathrm{L})$ be the matrix consisting of 1 's and o's, and the element of $\check{\mathrm{u}}(\mathrm{L})$ such that the static model in equations 1 and 2 is rewritten in terms of $\mathrm{F}_{\mathrm{t}}$

$$
\begin{aligned}
& \mathrm{X}_{\mathrm{t}}=\Lambda \mathrm{F}_{\mathrm{t}}+\mathrm{e}_{\mathrm{t}}(3) \\
& \mathrm{u}(\mathrm{L}) \mathrm{F}_{\mathrm{t}}=\mathrm{Gv}_{\mathrm{t}}(4)
\end{aligned}
$$

Where $G$ is a matrix of 1's and o's selected so that equation 2 and 4 are equal. Furthermore, it is assumed that $e_{t}$ follow the following process:

$$
\mathrm{d}_{\mathrm{i}}(\mathrm{L}) \mathrm{e}_{\mathrm{t}}=\zeta_{\mathrm{it}}, \mathrm{i}=1, \ldots, \mathrm{N} .(5)
$$

With the assumption that $\zeta_{\mathrm{it}}$ is independent and indirectly distributed, $\mathrm{N}\left(0, \sigma_{\zeta_{\mathrm{i}}}^{2}\right), \mathrm{i}=1, \ldots, \mathrm{N}$ and $\mathrm{v}_{\mathrm{t}}$ is independent and indirectly distributed, $\mathrm{N}\left(0, \sigma_{\mathrm{v}_{\mathrm{j}}}^{2}\right), \mathrm{j}=1, \ldots, \mathrm{q}$ and $\left\{\zeta_{\mathrm{t}}\right\}$ and $\left\{\mathrm{v}_{\mathrm{t}}\right\}$ are independent. Given these parameters, the Kalman filter can be used to compute the maximum likelihood and to estimate the filtered values of $F_{t}$ and $f_{t}$.

The Kalman filter is a recursive process constructed on the error $\mathrm{z}_{\mathrm{t}}^{*}$ and factor matrix $\mathrm{f}_{\mathrm{t}}^{*}$ over time. This is done by systematically updating the mean's conditional distribution $\alpha_{t} \mid F_{t} \sim N\left(a_{t \mid t}, P_{t \mid t}\right)$ and the conditional distribution of variances $\alpha_{t+1} \mid F_{t} \sim N\left(a_{t+1 \mid t}, P_{t+1 \mid t}\right)$ depicted in the following process as shown in the paper by Katzfuss (2016):

$$
\begin{gathered}
\mathrm{a}_{\mathrm{t} \mid \mathrm{t}}=\mathrm{a}_{\mathrm{t} \mid \mathrm{t}-1}+\mathrm{P}_{\mathrm{t} \mid \mathrm{t}-1} \mathrm{H}_{\mathrm{t}}{ }_{\mathrm{t}} \mathrm{F}_{\mathrm{t}}^{-1} \mathrm{v}_{\mathrm{t}},(6) \\
\mathrm{P}_{\mathrm{t} \mid \mathrm{t}}=\mathrm{P}_{\mathrm{t} \mid \mathrm{t}-1}+\mathrm{P}_{\mathrm{t} \mid \mathrm{t}-1} \mathrm{H}_{\mathrm{t}}^{\prime} \mathrm{F}_{\mathrm{t}}^{-1} \mathrm{H}_{\mathrm{t}} \mathrm{P}_{\mathrm{t}},(7) \\
\mathrm{a}_{\mathrm{t}+1 \mid \mathrm{t}}=\mathrm{T}_{\mathrm{t}} \mathrm{a}_{\mathrm{t} \mid \mathrm{t}},(8) \\
\mathrm{P}_{\mathrm{t}+1 \mid \mathrm{t}}=\mathrm{T}_{\mathrm{t}} \mathrm{P}_{\mathrm{t} \mid \mathrm{t}} \mathrm{T}^{\prime}{ }_{\mathrm{t}}+\mathrm{R}_{\mathrm{t}} \sum_{\mathrm{t}} \mathrm{R}_{\mathrm{t} \cdot}^{\prime} \cdot(9)
\end{gathered}
$$

Where $H_{t}$ is a $\left(\mathrm{N} \mathrm{x} \mathrm{k)} \mathrm{probabilistic} \mathrm{time-varying} \mathrm{matrix,} \mathrm{and} \mathrm{T}_{\mathrm{t}}\right.$ is a $(\mathrm{k} \mathrm{x})$ probabilistic time-varying matrix, these are also known as transition matrices. The filtered estimate of $\alpha_{t}$ is depicted in terms of $a_{t \mid t}$ and $a_{t+1 \mid t}$ is the one period ahead forecast of $\alpha_{t}$. $P_{t \mid t}$ shows the covariance matrix of each corresponding predicted value $a_{t \mid t}$. This recursive process will allow the coefficient estimations of $\mathrm{T}_{\mathrm{t}}, \mathrm{H}_{\mathrm{t}}, \sum \epsilon$ and $\sum \mathrm{\eta}$ by means of the log-likelihood function inbuilt into the Kalman filter (Harvey, 1989). To ensure that there are no bias loadings due to non-stationarity, the variables 
subjected to the DFM will be differenced where necessary to ensure that each variable is stationary (Stock and Watson, 2011). Brooks (2019) suggests that only factors with eigenvalues larger than one are worthwhile considering. The reasoning behind this is that components with eigenvalues larger than one encapsulate information of more than one variable. Hence, only common factors larger than one will be considered

As suggested by Chao and $\mathrm{Wu}$ (2017), the Eigenvalues and factor loadings will be used to determine the weights of each constituent towards the final Australasian financial conditions index. If there's only one factor with an Eigenvalue larger than one, the weightings will be calculated as follows (Chao and $\mathrm{Wu}, 2017$ ):

$$
\mathrm{W}_{\mathrm{X}}=\left(\frac{\mathrm{L}_{\mathrm{X}}}{\sum \mathrm{L}_{\mathrm{i}>0.4}}\right) * 100(10)
$$

Where $L_{X}$ represents the factor loading exhibited by variable $X_{i}$ and $\sum L_{i}$ is the sum of the factor loadings of all the variables with an absolute loading value greater than 0.4. The Australasian financial conditions index will then be calculated as follows:

$$
\text { Index }_{\mathrm{AFCI}}=\sum \mathrm{X}_{\mathrm{i}}\left(\mathrm{W}_{\mathrm{X}}\right)(11)
$$

Where Index ${ }_{\mathrm{AFCI}}$ is the Australasian financial conditions index. The Christiano Fitzgerald Band-pass filter will be implemented to extract cycles from the Australasian financial conditions index.

\subsection{Christiano Fitzgerald Band-pass filter:}

The CF Band-pass filter are calculated as follows (Christiano and Fitzerald, 2003):

where,

$$
c_{t}=B_{0} y_{t}+B_{1} y_{t+1}+\cdots+B_{T-1-t} y_{T-1}+\tilde{B}_{T-t} y_{T}+B_{1} y_{t-1} \cdots+B_{t-2} y_{2}+\tilde{B}_{t-1} y_{1}(12)
$$

$$
\begin{gathered}
B_{j}=\frac{\sin (j b)-\sin (j a)}{\pi j}, j \geq 1, \text { and } B_{0}=\frac{b-a}{\pi}, a=\frac{2 \pi}{p_{u}}, b=\frac{2 \pi}{p_{l}},(13) \\
\tilde{B}_{k}=-\frac{1}{2} B_{0}-\sum_{j=1}^{k-1} B_{j}(14)
\end{gathered}
$$

$p_{u}$ is the lower limit of the cyclical duration and $p_{l}$ depicts is the upper limit of the cyclical duration. The bandpass will range from two years to 32 years. Thus the $\mathrm{CF}$ filters will isolate and extract aggregate Australasian financial cycles with durations ranging from two years to 32 years. Two years is chosen as a lower band in case the aggregate Australasian financial cycle have similar durations than a typical business cycle, which typically range from two to eight years (Botha, 2006). On the other hand, empirical evidence shows that financial cycles can last up to 32 years, hence 32 years as an upper limit (Claessens et al., 2012). Cyclical movements with a duration lower than two years will be eliminated by the filters to eliminate any potential short-term noise.

\subsection{Markov-regime switching autoregressive model}

In literature, MS-AR models are often categorised by means of their regime dependent parameters (Bouali et al., 2016 and Tastan and Yildrim, 2008). The base model assumes that the mean and the variance are non-regime dependent. Such a model in this study has the following specification (Kim, 1994 and Hamilton, 1989):

$$
y_{t}=\beta_{s 1}\left(y_{t-1}+y_{t-2}+\cdots+y_{t-k}+x_{t}\right)+\beta_{s 2}\left(y_{t-1}+y_{t-2}+\cdots+y_{t-k}+x_{t}\right)+\varepsilon_{t}(15)
$$

Where $s_{t} \in\{1,2\}$ shows the regime state under consideration, $k$ shows the optimal lag length, $\varepsilon_{t}$ is a non-state dependent error term, and $x_{t}$ is a vector of explanatory variables. To allow for a regime-switching mean, equation 15 can be restated as follows (Bouali et al., 2016 and Tastan and Yildrim, 2008):

$$
y_{t}=c_{t s}+\beta_{s 1}\left(y_{t-1}+y_{t-2}+\cdots+y_{t-k}+x_{t}\right)+\beta_{s 2}\left(y_{t-1}+y_{t-2}+\cdots+y_{t-k}+x_{t}\right)+\varepsilon_{t}(16)
$$

Where $C_{t s}$ is a state-dependent intercept. Lastly, equation 15 can be restated to account for both a regime-switching mean and a regime-switching variance:

$$
y_{t}-\mu_{s t}=c_{t s}+\beta_{s 1}\left(y_{t-1}+y_{t-2}+\cdots+y_{t-k}+x_{t}-\mu_{s t-1}\right)+\beta_{s 2}\left(y_{t-1}+y_{t-2}+\cdots+y_{t-k}+x_{t}-\mu_{s t-2}\right)+\varepsilon_{t}
$$

Assuming that $S_{t}$ is a first-order Markov process, as done by Hamilton (1989), indicating that the current regime is a function of the previous regime $S_{t-1}$, then the transition probabilities of progressing from one regime to another regime can be stated as (Tastan and Yildrim, 2008):

$$
p_{i j}=\operatorname{Pr}\left(S_{t}=j \mid S_{t-1}=i\right), \sum_{j=1}^{n} p_{i j}=1, \forall i, j \in\{1,2, \ldots, n)(18)
$$

\section{Results and findings}

The first section will consider the characteristics of the Australian and New Zealand credit and property cycle. These measures are then aggregated and discussed. Figure 1 depicts the Australian and New Zealand property and credit cycles.

Figure 1: Australian and New Zealand property and credit cycles 

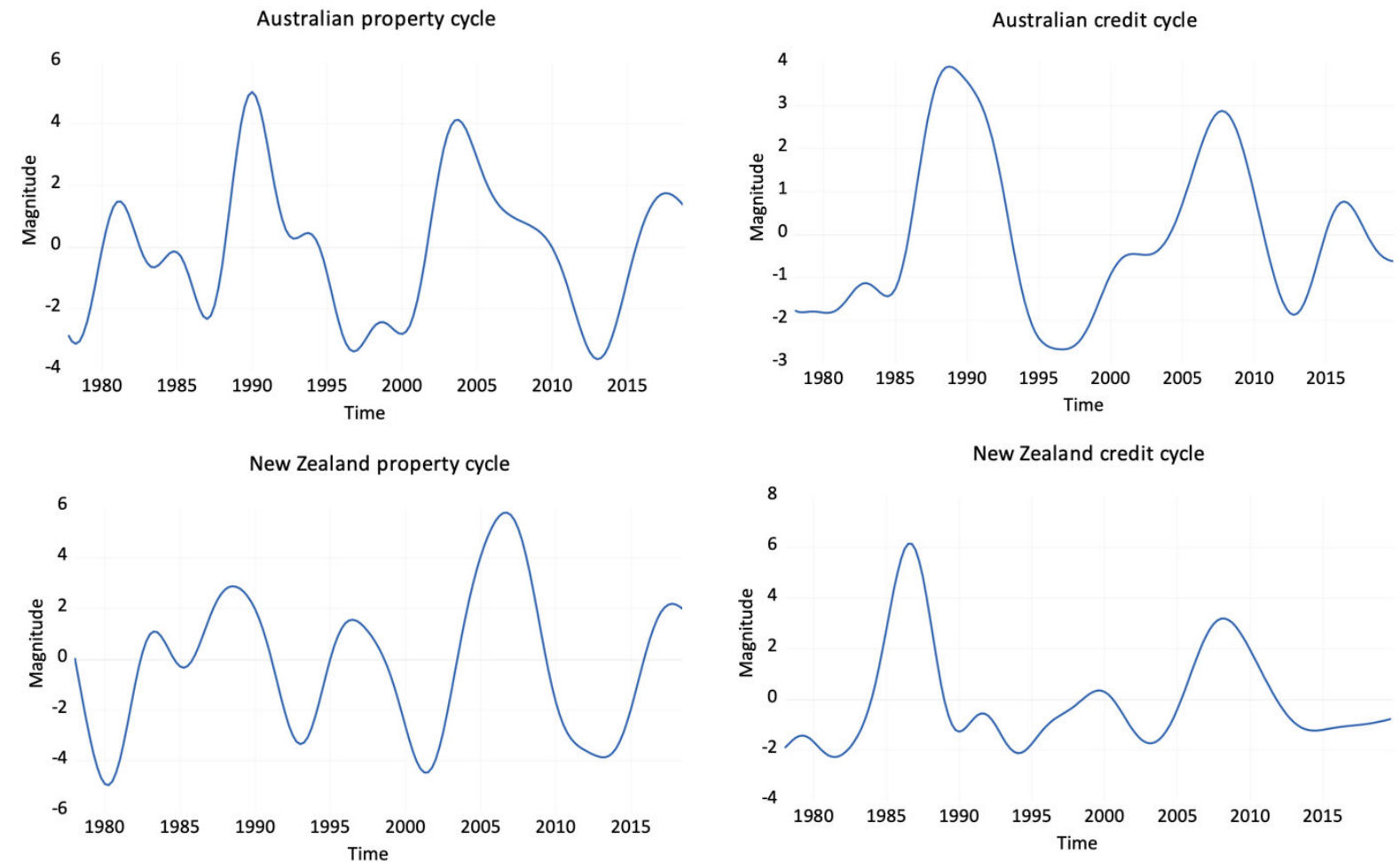

Source: Author's construction

Table 1 depicts the MS-AR results for the various cyclical aggregate Australasian financial cycle factors. The regimedependent means of both regimes, $\mu_{\mathrm{s} 1}$ and $\mu_{\mathrm{s} 2}$, for all four cyclical measures are statistically significant at a $99 \%$ confidence level and have opposite signs. This indicates that the point estimates of the mean in each regime differ significantly from each other, supporting the assumption that each one of these cyclical measures is characterised by two distinct regimes (Li, Lin and Hsiu-Hua, 2005 and Layton and Katsuura, 2001). This provides justification for the implementation of non-linear techniques to estimate these cycles. Provided that $\mu_{\mathrm{s} 1}>\mu_{\mathrm{s} 2}$, whereby $\mu_{\mathrm{s} 1}$ is positive and $\mu_{\mathrm{s} 2}$ is negative, regime one can be interpreted as the growth or expanding regime of these cycles and regime two as the corrective or contracting regime (Tastan and Yildirim, 2008).

Table 1: Estimation outputs for Australian and New Zealand credit and property cycles

\begin{tabular}{|c|c|c|c|c|}
\hline Variable & $\begin{array}{c}\text { Australian } \\
\text { credit cycle }\end{array}$ & $\begin{array}{c}\text { Australian } \\
\text { property cycle }\end{array}$ & $\begin{array}{l}\text { New Zealand } \\
\text { credit cycle }\end{array}$ & $\begin{array}{c}\text { New Zealand } \\
\text { property cycle }\end{array}$ \\
\hline$\mu_{s 1}$ & $0.038^{* * * *}$ & $0.053^{* * *} *$ & $0.155^{* * * *}$ & $0.085^{* * * *}$ \\
\hline$\mu_{s 2}$ & $-0.049^{* * *}$ & $-0.070^{* * *}$ & $-0.222 * * *$ & $-0.077^{* * *}$ \\
\hline$\beta_{1 s 1 t-1} \mathrm{AR}(1)$ & $1.006^{* * * *}$ & $1.495^{* * * *}$ & $1.633^{* * * *}$ & $1.531^{* * * *}$ \\
\hline$\beta_{2 s 1} \mathrm{AR}(2)$ & $0.746^{* * * *}$ & $1.174^{* * * *}$ & $-0.979^{* *}$ & $1.134^{* * * *}$ \\
\hline$\beta_{3 s 1} \mathrm{AR}(3)$ & & $-0.977^{*} *$ & & $-1.177^{* * *}$ \\
\hline$\beta_{1 s 2} \operatorname{AR}(1)$ & $1.538^{* * * *}$ & $0.865 * *$ & $1.048^{* * *}$ & $2.038^{* * * *}$ \\
\hline$\beta_{2 s 2} \operatorname{AR}(2)$ & $0.965 * * *$ & $-0.642^{* *}$ & $0.489^{* *}$ & $0.748^{* *}$ \\
\hline$\beta_{3 s 2} \operatorname{AR}(3)$ & $-0.665^{*} *$ & $0.977 * *$ & & $-0.827 * *$ \\
\hline$\sigma_{s 1}$ & $-7.076^{* * * *}$ & $-7.831 * * *$ & $-6.034 * * *$ & $-3.523 * * *$ \\
\hline$\sigma_{s 2}$ & $-7.455^{* * * *}$ & $-8.198 * * *$ & $-6.919^{* * * *}$ & $-2.764 * * *$ \\
\hline \multicolumn{5}{|c|}{ Transition Matrix Parameters } \\
\hline $\mathrm{P} 11-\mathrm{C}$ & $2.583^{*} * *$ & $3.508 * * *$ & $3.174 * * *$ & $2.751^{* * * *}$ \\
\hline $\mathrm{P} 21-\mathrm{C}$ & $-2.908^{* * * *}$ & $-3.014^{* * * *}$ & $-2.594 * * *$ & $-2.858 * * *$ \\
\hline \multicolumn{5}{|c|}{ Typical duration (in quarters) } \\
\hline Regime 1 & 31.620 & 28.382 & 24.910 & 16.662 \\
\hline Regime 2 & 29.514 & 21.359 & 14.380 & 18.429 \\
\hline
\end{tabular}




\begin{tabular}{|c|c|c|c|c|}
\hline Full cyclical duration & 60.710 & 49.740 & 39.290 & 35.091 \\
\hline \multicolumn{5}{|c|}{ Transition probabilities } \\
\hline$p_{11}$ & 0.930 & 0.971 & 0.959 & 0.939 \\
\hline$p_{12}$ & 0.070 & 0.029 & 0.042 & 0.060 \\
\hline$p_{22}$ & 0.948 & 0.953 & 0.930 & 0.946 \\
\hline$p_{21}$ & 0.052 & 0.047 & 0.070 & 0.054 \\
\hline
\end{tabular}

**, and *** denote statistical significance at a $95 \%$, and $99 \%$ confidence level, respectively, based on p-values. Source: Author's calculation

Furthermore, the variance parameters, $\sigma_{\mathrm{s} 1}$ and $\sigma_{\mathrm{s} 2}$ of all four cycles are statistically significant with varying magnitudes across regimes. In absolute terms, the variance parameters of the Australian and New Zealand credit cycle, as well as the Australian property cycle prove to be larger during a contraction relative to an expansion. Thus indicating that contractions in these cycles are more volatile than expansions. In contrast, the New Zealand property cycle proves to be more volatile during an expansion relative to a contraction given that $\sigma_{\mathrm{s} 1}<\sigma_{\mathrm{s} 2}$ in absolute terms (Kuan, 2002).

Statistically significant AR terms for all four cycles provide evidence that preceding periods in these cycle significantly affect the current state of these cycles. This is the case for both expanding and contracting regimes. Positive AR terms, particularly $\operatorname{AR}(1)$ terms, suggests that a level of linear presence exist in these cycles from one quarter to the next (Kuan, 2002). This corresponds to the transition probabilities, $\mathrm{p}_{11}$ and $\mathrm{p}_{22}$, which provide evidence that the conditional probability of remaining in either an expansion or contracting regime is larger than transitioning to another regime, reflected by $\mathrm{p}_{12}$ and $\mathrm{p}_{21}$.

Furthermore, the results indicate that an expansion in the Australian credit cycle typically lasts 31.2 quarters and a contraction lasts 29.51 quarters. Thus, a full cycle lasts an estimated 60.71 quarters. An expansion in the Australian property cycle typically lasts 28.38 quarters and a contraction lasts 21.36 quarters. Thus, a full cycle lasts an estimated 49.74 quarters. An expansion in the New Zealand credit cycle typically lasts 24.91 quarters and a contraction lasts 14.38 quarters. Thus, a full cycle lasts an estimated 39.29 quarters. An expansion in the New Zealand property cycle typically lasts 16.66 quarters and a contraction lasts 18.43 quarters. Thus, a full cycle lasts an estimated 35.09 quarters.

The results indicate that, with the exception of the New Zealand property cycle, expansions typically last longer than contractions in these cycles. Furthermore, the Australian credit cycle proves to exhibit the longest cyclical durations, where a full cycle typically lasts 60.71 quarters, or 15 years and 2 months. This is longer than the typical business cycle, aligning with the findings by Claessens, et al. (2012), Borio (2014), Aikman et al. (2015), Pontines (2017) and Farrell and Kemp (2020).

\subsection{The aggregate Australasian financial cycle}

Table 2 depicts the outputs rendered by the dynamic factor model. The results indicate that only the first factor has an Eigenvalue larger than 1, therefore, only the factor loadings onto factor one will be considered. The first factor captures about $69 \%$ of the variance between the various aggregate Australasian financial Measures. This is in line with the suggested appropriate level of $50 \%$ by Breitung and Eickmeier (2005), and the suggested level of $55 \%$ by $\mathrm{Ng}$ (2011). This provides evidence that there is a significant portion of the fluctuations between the various financial components that are systemic or syncretic. Thus, these variables can be well represented by a single measure, for example, an index.

Table 2: Dynamic factor outputs

\begin{tabular}{|c|c|c|c|}
\hline \multicolumn{4}{|c|}{ Eigenvalues of factors } \\
\hline Factor one & Factor two & \multicolumn{2}{|c|}{ Variance explained by factor one } \\
\hline 3.165 & 0.951 & \multicolumn{2}{|c|}{$69.146 \%$} \\
\hline \multicolumn{4}{|c|}{ Factor loadings } \\
\hline \multicolumn{2}{|c|}{ Variable } & Loading & Weighting \\
\hline \multicolumn{2}{|c|}{ Australian credit measure } & 0.753 & $30.810 \%$ \\
\hline \multicolumn{2}{|c|}{ New Zealand credit measure } & 0.642 & $26.268 \%$ \\
\hline \multicolumn{2}{|c|}{ Australian property measure } & 0.575 & $23.527 \%$ \\
\hline \multicolumn{2}{|c|}{ New Zealand property measure } & 0.474 & $19.394 \%$ \\
\hline
\end{tabular}

more, the results indicate that the Australian credit measure has the largest factor loading and will constitute $30.81 \%$ towards the Australasian financial conditions index, which is the largest contribution towards this index. This is 
followed by the New Zealand credit measure which contributes 26.268\% towards the index. Australian credit levels are thus the strongest underlying driver of the Australasian financial conditions index, and ultimately the strongest driver of the aggregate Australasian financial cycle. Figure 2 depicts the Australasian financial cycle.

Figure 2: the Australasian financial cycle

Australasian financial cycle

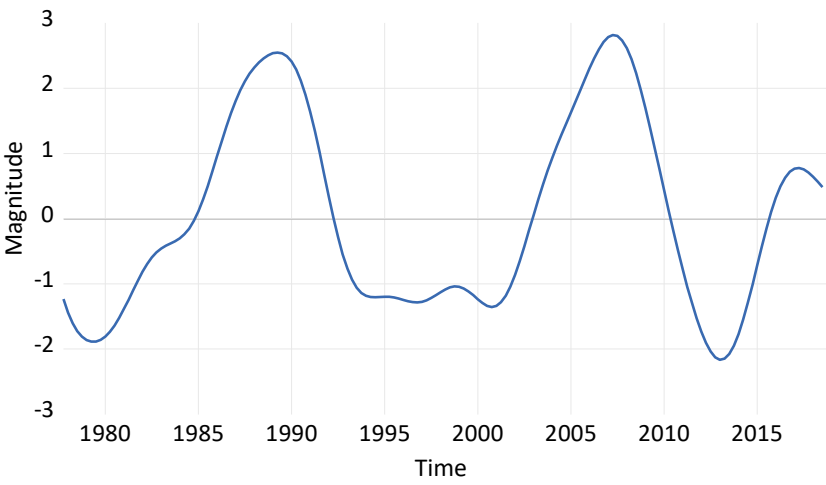

Source: Author's construction

Table 3 depicts the estimated MS-AR outputs for the Australasian financial cycle. The significant difference in the mean and variance across regimes justifies the use of a non-linear model. Similar to the other cyclical measures considered previously, given that $\mu_{\mathrm{s} 1}>\mu_{\mathrm{s} 2}$, regime one represents a growth or expanding regime in the aggregate Australasian financial cycle and regime two represents a corrective or contracting regime (Tastan and Yildirim, 2008). The results also indicate that a contracting regime is slightly more volatile than an expanding regime, given that $\sigma_{\mathrm{s} 1}<\sigma_{\mathrm{s} 2}$ in absolute terms. Therefore, similar to the research on business cycles, such as the findings by McQueen and Thorley (1993), Tastan and Yildirim (2008) and Breitung and Eickmeier (2015), contractions in the Australasian financial cycle prove to be more volatile than expansions.

Table 3: MS-AR estimation output for the Australasian financial cycle

\begin{tabular}{|c|c|c|c|}
\hline \multicolumn{2}{|c|}{ Variable } & \multicolumn{2}{|c|}{ The aggregate Australasian financial cycle } \\
\hline$\mu_{s 1}$ & & \multicolumn{2}{|c|}{0.019} \\
\hline$\mu_{s 2}$ & & \multicolumn{2}{|c|}{-0.014} \\
\hline$\beta_{1 s 1 t-1} \mathrm{AR}(1)$ & & \multicolumn{2}{|c|}{1.450} \\
\hline$\beta_{2 s 1} \operatorname{AR}(2)$ & & \multicolumn{2}{|c|}{0.965} \\
\hline$\beta_{1 s 2} \operatorname{AR}(1)$ & & \multicolumn{2}{|c|}{1.519} \\
\hline$\beta_{2 s 2} \operatorname{AR}(2)$ & & \multicolumn{2}{|c|}{0.935} \\
\hline$\sigma_{s 1}$ & & \multicolumn{2}{|c|}{-4.022} \\
\hline$\sigma_{s 2}$ & & \multicolumn{2}{|c|}{-4.739} \\
\hline \multicolumn{4}{|c|}{ Transition Matrix Parameters } \\
\hline $\mathrm{P} 11-\mathrm{C}$ & & \multicolumn{2}{|c|}{2.928} \\
\hline $\mathrm{P} 21-\mathrm{C}$ & & \multicolumn{2}{|c|}{-2.709} \\
\hline \multicolumn{4}{|c|}{ Typical duration (in quarters) } \\
\hline Regime 1 & & \multicolumn{2}{|c|}{24.835} \\
\hline Regime 2 & & \multicolumn{2}{|c|}{19.700} \\
\hline Full cyclical dur & & \multicolumn{2}{|c|}{44.535} \\
\hline \multicolumn{4}{|c|}{ Transition probabilities } \\
\hline & & \multicolumn{2}{|c|}{0.949} \\
\hline \multicolumn{2}{|c|}{$p_{12}$} & \multicolumn{2}{|c|}{0.041} \\
\hline \multicolumn{2}{|c|}{$p_{22}$} & \multicolumn{2}{|c|}{0.938} \\
\hline \multicolumn{2}{|c|}{$p_{21}$} & \multicolumn{2}{|c|}{0.073} \\
\hline \multicolumn{4}{|c|}{ Wald hypothesis testing asymmetry results } \\
\hline Asymmetry & Sign & Null hypothesis & P-value \\
\hline
\end{tabular}




\begin{tabular}{|c|c|c|c|}
\hline Sharpness & N/A & $\boldsymbol{H}_{\mathbf{0}}: \boldsymbol{p}_{\mathbf{1 2}}=\boldsymbol{p}_{\mathbf{2 1}}$ & $0.031^{* *}$ \\
\hline Deepness & Positive & $\boldsymbol{H}_{\mathbf{0}}:$ Non-deepness & $0.002^{* * * *}$ \\
\hline Steepness & Negative & $\boldsymbol{H}_{\mathbf{0}}:$ Non-steepness & $0.071^{*}$ \\
\hline
\end{tabular}

**, and *** denote statistical significance at a 95\%, and $99 \%$ confidence level, respectively, based on p-values. Source: Author's calculation

The results further provide evidence of linear persistence in both regimes, given the positive and significant autoregressive terms. Thus, a positive movement in either regime will typically result in positive movements in the proceeding two quarters. This is substantiated by the transition probabilities, $\mathrm{p}_{11}$ and $\mathrm{p}_{22}$, which provide evidence that the conditional probability of remaining in either an expansion or contracting regime is larger than transitioning to another regime, reflected by $\mathrm{p}_{12}$ and $\mathrm{p}_{21}$. This shows that self-reinforcing forces exist in the cycle. The results indicate that expansions in the aggregate Australasian financial cycle typically exhibit a duration of 24.835 quarters, or 6 years and 3 months, and contractions a duration of 19.700 quarters, or 4 years and 11 months. Thus, the typical duration of an entire cycle from peak to peak or trough to trough is 44.535 quarters, or 11 years and 2 months.

The Australasian financial cycle typically exhibits a duration longer than the business cycle, where the duration of business cycles typically range from two to eight years (Strohsal et al., 2019 and Schüler et al., 2019). This corresponds with findings in the literature that financial cycles typically have longer durations than business cycles, see for example $\mathrm{Ng}$ (2011), Claessens, et al. (2012), Borio (2014), Aikman et al. (2015), Pontines (2017) and Farrell and Kemp (2020). It also shows that the duration of expansions in the cycle typically has a duration that is one year and four months longer than contractions. The Australasian financial cycle thus exhibits a level of cyclical duration asymmetry and corresponds with literature that provides evidence that cyclical expansions last longer than contractions, see for example McQueen and Thorley (1993), Tastan and Yildirim (2008) and Breitung and Eickmeier (2015).

Furthermore, the bottom part of Table 3 depicts the results from the Wald hypothesis testing process conducted in the MS-AR model, to test for Sharpness, deepness and steepness asymmetries in the aggregate Australasian financial cycle. This is done in accordance with Clements and Krolzig (2003). Firstly, the non-sharpness test provided a p-value of 0.031 , the null hypothesis is therefore rejected at a $95 \%$ confidence level. Therefore $\mathrm{p}_{12} \neq \mathrm{p}_{21}$ and the probability of moving from a contraction to an expansion, with a $7.3 \%$ probability, is larger than moving from an expansion to a contraction, with a $4.1 \%$ probability. A sharpness asymmetry thus exists in the aggregate Australasian financial cycle.

Secondly, the non-deepness test has a p-value of 0.002 with positive skewness, thus, the null hypothesis of nondeepness are rejected at a 99\% confidence level. This provides evidence that peaks in the aggregate Australasian financial cycle are typically higher than troughs. This finding contrasts the general findings in business cycle literature which suggests that troughs are deeper than peaks (McQueen and Thorley, 1993; Tastan and Yildirim, 2008 and Breitung and Eickmeier, 2015). This could be due to the extended duration of financial cycles relative to business cycles. Lastly, the non-steepness test has a p-value of 0.071 with a negative skewness, thus, the null hypothesis of non-steepness are rejected at a $90 \%$ confidence level. Therefore, the slope of contractions in the aggregate Australasian financial cycle is typically steeper than the slope of expansions.

\section{Conclusion}

This study aimed to construct and characterise the aggregate Australasian financial cycle. To this end, a dynamic factor model and a Markov-regime switching model were implemented. This study contributes by providing a single aggregate financial cycle measure that could be used to simplify the analysis of Australasian financial cycles. Furthermore, this study contributes by being the first academic study to construct and holistically analyse both the financial cycle of Australia and New Zealand, adding to the current understanding of financial cycles. In addition, this study contributes by modelling the Australasian financial cycle with a non-linear Markov Regime-Switching model. This provides a formal econometric approach to characterise the cycle and identifying asymmetries in the cycle.

The main findings in this study are that levels of Australian credit aggregates, followed by New Zealand credit aggregates, are the primary underlying driver of aggregate Australasian financial conditions. The Australian credit cycle exhibits the longest duration, followed by the Australian property cycle, the New Zealand credit cycle and lastly, the New Zealand property cycle, with typical durations of 61 quarters, 50 quarters, 39 quarters and 35 quarters respectively. The typical duration of a full cyclical movement in the aggregate Australasian financial cycle is about 45 quarters, with expansions typically exhibiting durations of 25 quarters and contractions typically exhibiting durations of 20 quarters. Contractions in the aggregate Australasian financial cycle tends to be more volatile, with steeper slopes than expansions. Furthermore, expansions tend to have a larger magnitude than contractions.

From these findings, several policy recommendations can be derived. Firstly, given that Australian credit levels are the primary underlying driver of financial conditions in this economic area, policymakers should pay particular attention to the Australian credit cycle. This cyclical measure, in correspondence with its characteristics, could be utilised to identify potential financial build-ups. Secondly, given the relatively longer durations exhibited by the aggregate Australasian financial cycle, policies targeted at financial cycle control, such as macroprudential policies, 
should adjust less frequently than policies aimed at business cycle control. Thirdly, asymmetries in the aggregate Australasian financial cycle require adjusted policy strategies, as well as adjustments in the timing of policy implementations during different cyclical regimes.

The asymmetrical duration in the aggregate Australasian financial cycle requires restrictive cyclical policies to be employed for longer periods than accommodative policies. Steeper contractions relative to expansions, accompanied by more volatility, necessitates a relatively quicker and stronger expansionary policy response during a contracting regime relative to restrictive policies during an expansion. This is due to the harshness and speed of a contraction. The deepness asymmetry in the aggregate Australasian financial cycle, whereby peaks exhibit a larger magnitude than troughs, could indicate that policymakers allow financial expansions to go too far. This, in turn, might partly contribute to the relatively harsh contractions exhibited by the cycle. Policymakers should consider implementing restrictive policies sooner in the expansion phase in order to limit unsustainable build-ups and thereby reducing the harshness of a contraction.

\section{References}

Adarov, A. (2018). Financial Cycles Around the World. Working paper 145, Vienna Institute of International Economic Studies. Aikman, D., Haldane, A.G, \& Nelson, B.D. (2015). Curbing the Credit Cycle. The Economic Journal, $125(85)$, pp. $1072-1109$.

Borio, C. (2014). The Financial Cycle and Macroeconomics: What have we Learnt? Journal of Banking and Finance, 45, pp.182198.

Bouali, M., Nasr, A.B. \& Trabelsi, A. (2016). A Nonlinear Approach for Modelling and Forecasting US Business Cycles. International Economic Journal, 30, pp. 39-74.

Breitung, J. \& Eickmeier, S. (2016). Analyzing international Business and Financial Cycles Using Multi-Level Factor Models: A Comparison of Alternative Approaches. Advances in Econometrics, 35, pp. 177-214.

Brooks, C. (2019). Introductory Econometrics for Finance, 4th edition. Cambridge University Press, Cambridge.

Cashin, P \& Ouliaris, S. (2004). Key features of Australian business cycles. Australian Economic Papers, 43, pp. 39-58.

Chao, Y. \& Wu, C. (2017). Principal Component-Based Weighted Indices and a Framework to Evaluate Indices: Results from the Medical Expenditure Panel Survey 1996 to 2011. PLOS One, 12(9), pp. 1-20.

Chauvet, M. \& Hamilton, J. (2006). Dating business cycle turning points. Milas, C., Rothman, P. and van Dijk, D., Nonlinear Time Series Analysis of Business Cycles, Elsevier, Amsterdam, pp. 1-53.

Chetwin, W. (2012). Business cycle review, 1998-2011. Reserve Bank of New Zealand Bulletin, 75, pp. 14-27.

Christiano, L. \& Fitzerald, T. (2003). The Band-Pass Filter. International Economic Review, 44(2), pp. 435-465.

Claessens, S., Kose, M.A. \& Terrones, M.E. (2012). How do Business Cycles and Financial Cycles Interact”, Journal of International Economics, 87, pp. 178-190.

Clements, M.P. \& Krolzig, H.M. (2003). Business cycle asymmetries: Characterization and testing based on Markov-switching autoregressions, Journal of Business and Economic Statistics, 21, pp. 196-211.

Crosby, M. (2002). The Australian Business Cycle: Joe Palooka or Dead Cat Bounce. Australian Economic Papers, 41, pp. 191-207

De Wet, M.C. \& Botha, I. (2019). Characterising cycles exhibited by important financial sections in the South African economy. Journal of Economic and Financial Sciences, 12, a433. https://doi.org/ 10.4102/jef.v12i1.433

Drehmann, M., Borio, C. \& Tsatsaronis, K. (2012). Characterising the Financial Cycle: Don't Lose Sight of the Medium Term. Working Paper: BIS, Monetary and Economics Department, No. 360.

English, W., Tsatsaronis, K. \& Zoli, E. (2005). Assessing the predictive power of measures of financial conditions for macroeconomic variables. BIS Papers 22, pp. 228-252.

Farrell, G. \& Kemp, E. (2020). Measuring the Financial Cycle in South Africa. South African Journal of Economics, 88, 2, pp. 123144

Goodwin, T. (1993). Business-cycle analysis with a Markov-switching model. Journal of Business Economics and Statistics, 11(3), pp. $331-339$

Hall, V.B., \& McDermott, C.J. (2009). The New Zealand business cycle. Econometric Theory, 25(4), pp. 1050-1069

Hamilton, J. D. (1989). A new approach to the economic analysis of nonstationary time series and the business cycle. Econometrica, 57 , pp. $357-384$.

Harvey, A.C. (1989). Forecasting, Structural Time Series Models and the Kalman Filter. Cambridge University Press: Cambridge.

Jorda, O., Schularick, M \& Taylor, A. (2016). The great mortgaging: housing finance, crises and business cycles. Economic Policy, $85(31)$, pp. $107-152$.

Katzfuss, M. (2016). Understanding the Ensemble Kalman Filter. The American Statistician, $70(4)$, pp. $350-357$.

Kim, K., Buckle, R.A., \& Hall, V.B. (1994). Key Features of New Zealand business cycles. Economic Record, $70(20)$, pp. 56-72.

Kim, K., Buckle, R.A., \& Hall, V.B. (1995). Dating New Zealand business cycles. New Zealand Economic Papers, 29 , pp. 143-171.

Korinek, A. (2017). Regulating Capital Flows to Emerging Markets: An Externality View. Journal of International Economics, 111 , pp. 61-80.

Layton, A.P. \& Katsuura, M. (2001). A New Turning Point Signaling System Using the Markov Switching Model with Application to Japan, the USA and Australia. Applied Economics, 33, pp. 59-70.

Layton, A.P. (1997). A New Approach to Dating and Predicting Australian Business Cycle Phase Changes, Applied Economics, 29, pp. $861-868$

Li, M.L., Lin, H.W. \& Hsiu-Hua. (2005). The Performance of the Markov-Switching Model on Business Cycles Identification Revised, Applied Economic Letters, 12, pp. 513-520.

McQueen, G., \& Thorley, S. (1993). Asymmetric business cycle turning points, Journal of Monetary Economics, 31, pp. 341-62.

Menden, C. \& Proano, C.R. (2017). Dissecting the Financial Cycle with Dynamic Factor Models, working paper 183, Monetary Policy Institute, University of Bamberg.

Moolman, E. (2004). A Markov Switching Regime Model of the South-African Business Cycle, Economic Modelling, 21 , pp. 631646.

Narayan, P.K. \& Pop, S. (2009). Investigating Business Cycle Asymmetries for the G7 Countries: Evidence from Over a Century of Data. International Review of Economics and Finance, 18, pp. 583-591. 
$\mathrm{Ng}$, T. (2011). The predictive content of financial cycle measures for output fluctuations, Bank for International Settlements, quarterly bulletin.

Pontines, V. (2017). The Financial Cycle in Four East Asian Economies, Economic Modelling, 65, pp. 51-66.

Sarbijan, M.S. (2014). Modelling Business Cycles with Markov Switching ARMA (Ms-Arma) Model: An Application on Iranian Business Cycles, International Journal of Management, Accounting and Economics, 3, pp. 201-214.

Schularick, M. \& Taylor, A. (2012). Credit booms gone bust: monetary policy, leverage cycles and financial crisis, $1870-2008$. American Economic Review, 102(2), pp. 1029-1061.

Schüler, Y.S., Hiebert, P.P. \& Peltonen, T.A. (2015). Characterising the Financial Cycle: a Multivariate and Time-Varying Approach, working paper 1846. European Central Bank.

Simpson, P.W., Osborn, D.R. \& Senier, M. (2001). Modelling Business Cycle Movements in the UK Economy, Economica, 69, pp. 243-267.

Stock, J. \& Watson, M.W. (2011). Dynamic Factor Models, Clements, M.P.and Hendry, D.F. Oxford Handbook on Economic Forecasting, Oxford University Press, Oxford.

Strohsal, T., Proaño, C.R. \& Wolters, J. (2019). Characterizing the Financial Cycle: Evidence from a Frequency Domain Analysis, Journal of Banking and Finance, 106, pp. 568-591.

Tastan, H. \& Yildirim, N. (2008). Business cycle asymmetries in Turkey: an application of Markov-switching autoregressions, International Economic Journal, 22(3), pp. 315-333.

This is an Open Access article distributed under the terms of the Creative Commons Attribution Licence 